\section{Renal angiomyolipomatosis and bleeding aneurysms in a tuber- ous sclerosis context: selective artery embolization in a girl with end-stage renal failure}

\author{
Gloria Pelizzo, ${ }^{1}$ Mario Giuseppe \\ Vallone, ${ }^{2}$ Mario Milazzo, ${ }^{3}$ Gregorio \\ Rosone, ${ }^{3}$ Salvatore Amoroso, ${ }^{3}$ Giovanni \\ Pavone, ${ }^{4}$ Maria Michela D'Alessandro, ${ }^{4}$ \\ Elettra Unti, ${ }^{5}$ Valeria Calcaterra ${ }^{6}$ \\ 1Department of Biomedical and Clinical \\ Science "L Sacco", University of Milan, \\ Department of Pediatric Surgery, \\ Children's Hospital V. Buzzi", Milan; \\ ${ }^{2}$ Operative Unit of Vascular Radiology \\ and Endovascular Therapy, ARNAS \\ Civico-Di Cristina-Benfratelli, Palermo; \\ 3Pediatric Unit, ARNAS Civico-Di \\ Cristina-Benfratelli, Palermo; \\ 4Pediatric Nephrology Unit, ARNAS \\ Civico-Di Cristina-Benfratelli, Palermo; \\ 5Pathology Unit, ARNAS Civico-Di \\ Cristina-Benfratelli, Palermo; \\ 'Pediatrics and Adolescents Unit, \\ Department of Internal Medicine \\ University of Pavia; Children's Hospital \\ "Vittore Buzzi", Milano, Italy
}

\section{Abstract}

Recent developments in endovascular radiological techniques and devices have rendered embolization a major therapeutic option prior to surgery in many renal vascular or neoplastic diseases. A 19-yearold female patient, with a diagnosis of tuberous sclerosis complex (TSC) in childhood, was admitted with severe anemia. Polycystic kidney disease in end-stage renal failure appeared four years before and the patient has been undergoing peritoneal dialysis. The patient's medical history also included bilateral renal angiomyolipomas (AMLs). One year earlier, a unilateral endovascular embolization was performed to repair a bleeding aneurysm at the right renal upper pole. A second bilateral ruptured renal aneurysm was diagnosed at admission. To continue with peritoneal dialysis and prevent intrarenal hemorrhage and intraperitonal bleeding, an urgent bilateral renal AE was performed. Two months later she underwent a bilateral retroperitoneal nephrectomy. The posterior surgical approach, preserved the peritoneal surface area and adequate conditions to continue dialysis. At histology, bilateral AMLs were confirmed and a renal cell carcinoma of the right kidney was concurrently discovered.
She undergoes continuous peritoneal dialysis. Urgent selective renal $\mathrm{AE}$ represents a feasible treatment for bilateral AML bleeding. It is safe and feasible before performing nephrectomy in patients with end-stage renal failure.

\section{Introduction}

Recent developments in endovascular radiological techniques and devices have rendered embolization a major therapeutic option prior to surgery in many renal vascular or neoplastic diseases. ${ }^{1,2}$ Renal artery embolization (AE) to treat proximal or distal renal vessel occlusion has a low morbidity and, when used to treat selective distal occlusions has a low impact on renal function compared to surgical procedures. In adults, indications for embolization in nephrology include post-biopsy arteriovenous fistulas, renal graft intolerance, functional exclusion and polycystic kidney disease before transplantation. ${ }^{1,2}$ Other conditions, such as arterial aneurysms, arteriovenous malformations and angiomyolipomas, mostly in tuberous sclerosis complex (TSC) have also been indicated. ${ }^{1}$

TSC is an autosomal dominant disorder with multisystem clinical manifestations. The brain, retina, kidneys, heart, and skin are most commonly affected. ${ }^{3-7}$ Angiomyolipomas, renal cysts, and renal cell carcinoma are classical features of renal involvement in TSC.8-9 Renal angiomyolipomas (AMLs) are found in 50$80 \%$ of TSC patients and are usually bilateral with a high female preponderance, suggesting a hormonal influence. $8,10-12$ Renal AML can increase in size by more than 3 $\mathrm{cm}^{13-15}$ which may lead to retro peritoneal hemorrhage and renal insufficiency. Renal cysts are found in around $20 \%$ of patients, but polycystic kidney disease, a relatively rare manifestation of TSC, is present in less than $2 \%$ cases. ${ }^{8,10-12} \mathrm{We}$ report a case of severe anemia, the result of spontaneous rupture of renal aneurysms, in a girl affected by TSC with bilateral AMLs and end-stage renal failure, who underwent bilateral artery embolization (AE) before a retro peritoneal nephrectomy in order to preserve conditions compatible with peritoneal dialysis.

\section{Case Report}

A 19-year-old female patient was admitted to our surgical unit with severe anemia (Hb $4.1 \mathrm{~g} / \mathrm{dL})$. Impaired growth was noted (weight $39.5 \mathrm{~kg}$; height $146 \mathrm{~cm}$; BMI $\left.17.6 \mathrm{~kg} / \mathrm{m}^{2}\right)$. She had a heart rate of 78 beats
Gloria Pelizzo, Pediatric Surgery Department "Vittore Buzzi" Children's Hospital, Via Lodovico Castelvetro 32, 20154 Milano, Italy. Tel.: +39.02-.7995435

E-mail: gloriapelizzo@gmail.com

Key words: renal artery embolization, angiomyolipoma, bleeding aneurysms, tuberous sclerosis context, end-stage renal failure.

Contributions: GPe surgical management of the patient, drafting the article, critical revision of the article; MGV radiological management and endovascular treatment; MM, GR, SA surgical management of the patient; GPa, MMSD nephrological management of the patient; EU histological analysis, drafting the article; VC drafting the article, literature review, critical revision of the article.

Conflict of interest: The authors declare no conflict of interest.

Funding: Self funding.

Availability of data and materials: All data generated or analyzed during this study are included in this published article.

Informed consent: Written informed consent was obtained.

Received for publication: 28 October 2019. Accepted for publication: 25 February 2020.

This work is licensed under a Creative Commons Attribution NonCommercial 4.0 License (CC BY-NC 4.0).

(C) Copyright: the Author(s), 2020

Licensee PAGEPress, Italy

Pediatric Reports 2020; 12:8352

doi:10.4081/pr.2020.8352

per minute, blood pressure of 226/136 $\mathrm{mmHg}$, respiration rate of 16 breaths per minute and arterial oxygen saturation of $96 \%$. Blood analysis showed a serum creatinine level of $10.97 \mathrm{mg} / \mathrm{dl}$ (nv 0.5-1.1) and urea $109 \mathrm{mg} / \mathrm{dL}$ (nv 16-46) mmol/L. The patient also presented with bilateral AMLs, hypertension and seizure disorder. Her relatives reported difficulty in managing her home medications (antihypertensive and antiepileptic drugs) due to her intellectual disability. The patient had been diagnosed with TSC in childhood; there was a paternal family history of TSC. Polycystic kidney disease (PKD) in end-stage renal failure appeared four years prior and the patient has been undergoing peritoneal dialysis since the diagnosis. At the age of 18 years, she underwent a prior unilateral endovascular embolization to treat renal aneurisms and the procedure successfully stopped a bleeding 
aneurism at the upper pole of the right kidney. Based on the patient's medical history, clinical and biochemical findings, a ruptured renal artery aneurysm was diagnosed. An urgent renal AE was considered the treatment of choice to limit hemorrhage and the risk of damage to the peritoneal dialysis catheter. The multidisciplinary team, including pediatric surgeons, interventional radiologists, pediatric nephrologists and psychologists agreed upon the choice to perform a bilateral renal $\mathrm{AE}$ in this complex patient. Prior to the intervention, and after being informed on the nature of the intervention, the patient and the patient's parents gave their written consent to undergo endovascular treatment. Under general anesthesia, ultrasound-guided right femoral common artery access was gained using a Terumo 6 FR $11 \mathrm{~cm}$ catheter. A diagnostic plain angiography scan revealed a double right renal artery. The major artery was easily catheterized with a 6 FR C2 Mac Boston-Scientific $6 \mathrm{~F}(65 \mathrm{~cm})$ catheter. Through this catheter, a AMplatzer Plug-2 $10 \mathrm{~mm}$ was released achieving artery occlusion (about $1 \mathrm{~cm}$ from the ostium, Figure 1A). A Sim1 Boston-Scientific $5 \mathrm{fr}$ was positioned in the lower right renal artery and several Terumo Azur coils were released (Figure 1B). Upon completion of the intervention, angiography confirmed the complete embolization of the vessels (Figure $1 \mathrm{C})$. The same procedure was used for the left renal embolization using a Cobra C2 catheter and Terumo 4x10 mm Azur coils (Figure 1D). With the final angiography, bilateral renal arterialthrombosis was confirmed (about $1 \mathrm{~cm}$ from the ostium, Figure 1D). The first $\mathrm{cm}$ of the renal artery was preserved to facilitate clamping during the future nephrectomy. After the procedure, the patient was transferred to the pediatric intensive care unit of our institution for observation and subsequently to the pediatric nephrology unit. Vital signs were monitored; her postoperative course was uneventful. Two months later, the patient underwent a bilateral lumbotomy and bilateral extraperitoneal nephrectomy to protect the peritoneal surface area and dialysis adequacy. Grossly, both kidneys were

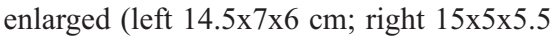
$\mathrm{cm}$ ); macroscopically the tissue was almost entirely replaced by cysts alternating with solid grey and brown areas, on a background of soft and yellowish tissue with calcific deposits. Histologically, solid areas on the yellowish background were revealed to be angiomyolipoma, which extended to the adipose tissue, perirenal and the renal pelvis. Partially solid aspects (epithelioid angiomyolipoma) and partially cystic aspects (cysts with cubic or hobnail

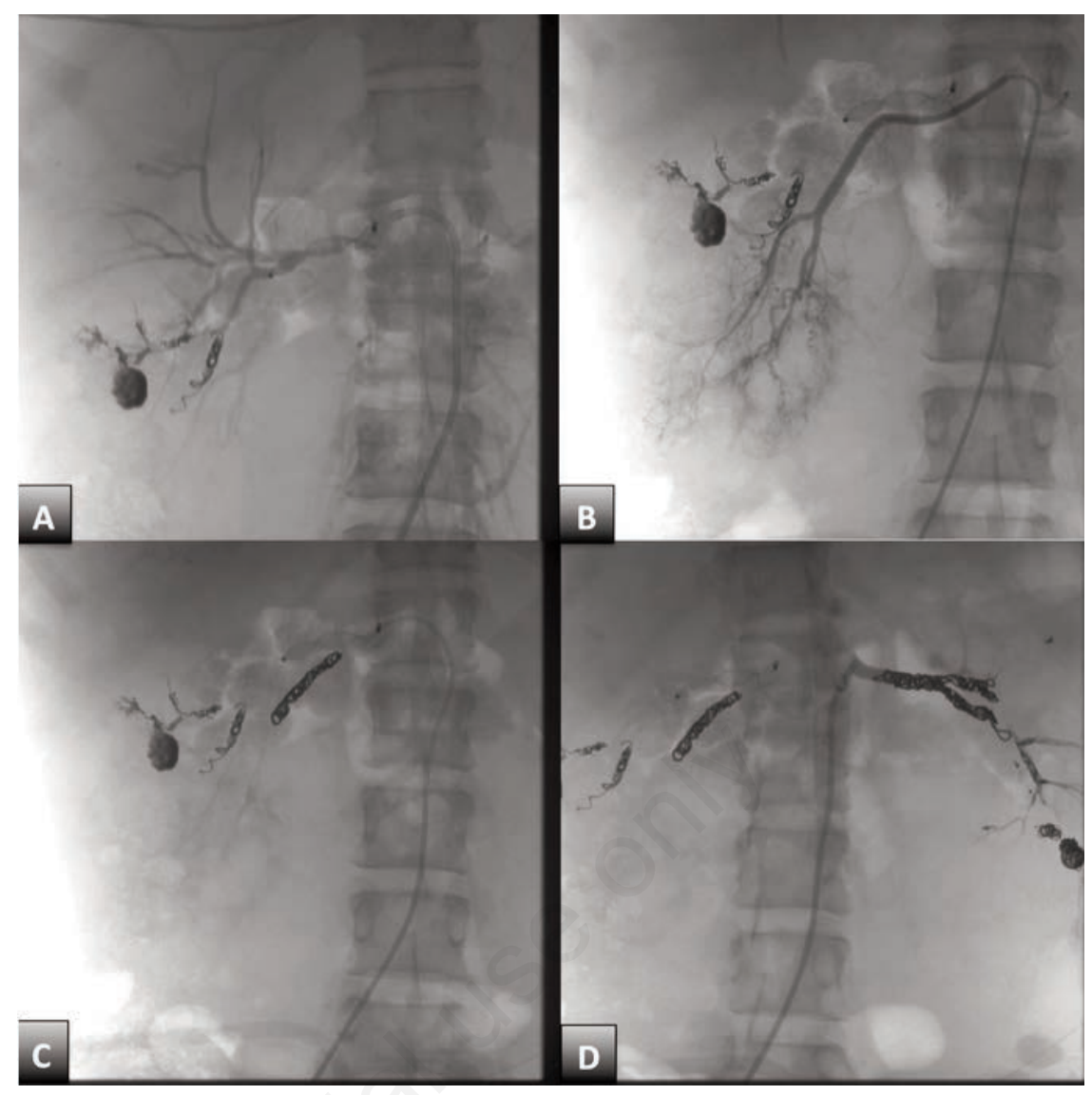

Figure 1. Bilateral renal artery embolization (AE). A: amplatzer-2 Plug $8 \mathrm{~mm}$ transcatheter release in the juxta-ostial tract of the right renal artery; B: selective catheterization of the lower right renal artery; $C$ : selective embolization of the lower right renal artery; D: selective left renal $\mathrm{AE}$ embolization and its lobar branches by transcatheter release of metal spirals.

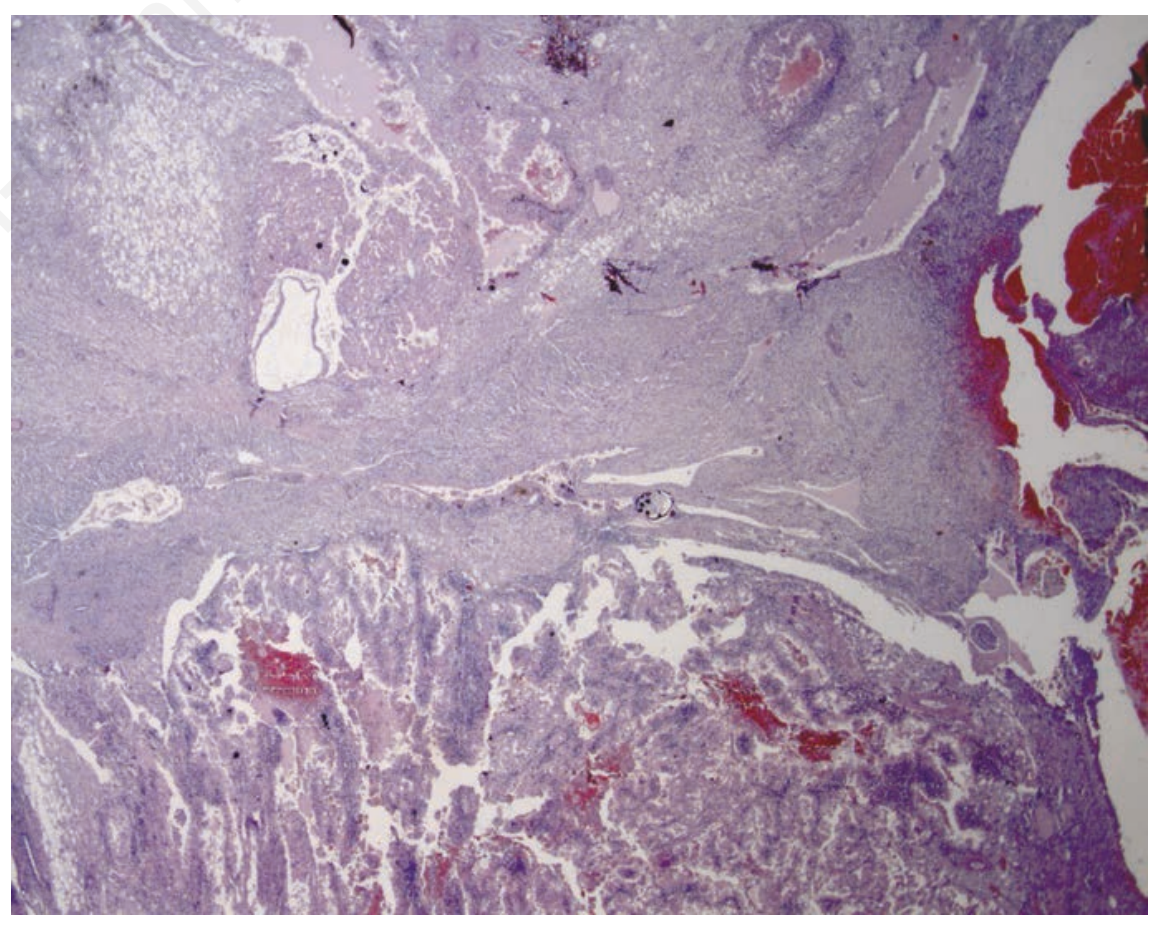

Figure 2. Histological aspect of the right kidney (Hematoxylin-eosin, original magnification X125): renal cell carcinoma on the bottom; solid portion of the angiomyolipoma at the top, its cystic portion on the right. 
epithelium) were observed. In the right kidney, other solid greyish areas were observed (maximum diameter $15 \mathrm{~mm}$ ); these were classified as renal cell carcinomas (RCC), with acinar, papillary and alveolar growth patterns and cribiform aspects, Furhrman grade III (Figure 2).

The patient was discharged on the fourth day of hospitalization in stable clinical condition. Her clinical condition and laboratory tests were stable at 12 months follow-up. The patient undergoes continuous peritoneal dialysis.

\section{Discussion}

Renal AMLs are found in $<0.3 \%$ of the general population and account for about $3 \%$ of all kidney tumors. ${ }^{16}$ The majority of AMLs occur sporadically (80-90\%) while the remaining cases are associated with TSC. ${ }^{13-17}$ Renal AMLs are composed of varying amounts of abnormal blood vessels, smooth muscle and adipose tissue. The blood vessels within AMLs are abnormal with no internal elastic lamina and the smooth muscle is replaced by fibrous tissue making the vessels rigid, tortuous and prone to aneurysm formation and rupture. ${ }^{17}$ The main morbidity associated with AML is spontaneous life-threatening hemorrhage, which can be retroperitoneal or present with visible hematuria. Encroachment into the normal renal tissue, leading to renal failure may occur; but in most patients, as in our case, renal failure was due to PKD or loss of normal renal tissue due to multiple interventions to treat hemorrhage. ${ }^{9}$

Diagnosis and follow-up of TSCassociated renal AMLs are mainly based on imaging studies. These renal tumors are classically identified by the characteristic presence of fat observed with computed tomography (CT), magnetic resonance imaging or ultrasonography. ${ }^{17-18}$

Even though currently the optimal treatment for renal AML is debated, management recommendations are based on tumor size and symptoms, and treatment goals focus on preventing acute events, the preservation of the renal parenchyma and maintenance of long-term kidney function. ${ }^{10}$ According to Krueger et al 2013, selective AE may be considered the first line therapy for AML presenting with acute hemorrhage ${ }^{14}$ and nephrectomy should be avoided, ${ }^{14}$ except in selected cases. ${ }^{22,24-26}$ Recently, new immunosuppressive strategies, such as mTOR inihibitors 15,19-24 have been proposed for asymptomatic growing AML This strategy should reduce the size of the AML and the risk of rupture and bleeding, also in patients with end stage renal failure. ${ }^{19}$

Selective AE is the most commonly employed nephron sparing intervention for AML. Due to the availability of microcatheters and the superior image quality of diagnostic equipment, selective $\mathrm{AE}$ has gained popularity in both elective and emergency settings. ${ }^{1,15}$ Technical success has been defined as tumor vascular occlusion characterized by cessation of flow in the target vessels and lack of tumor staining. ${ }^{13}$ It is a technically feasible and minimally invasive procedure for controlling severe hemorrhage, improving clinical symptoms and preventing tumor progression in patients with renal AMLs. 13,17,26-27 We confirmed the feasibility of this approach also under urgent conditions and when renal failure was present. The risk of AML rupture is not exclusively associated with the lesion size; however, to limit the risk of retroperitoneal haemorrhage, prophylactic immunosuppressive interventions are recommended for AML with a diameter of $>3 \mathrm{~cm} \cdot{ }^{19-24}$ However, the efficacy and tolerability of everolimus in hemodialysis patients, with end-stage renal disease, remains controversial because the condition is thought to alter drug pharmacokinetics. ${ }^{28-}$ 33 Thus, we chose not to utilize this treatment in our patient.

Nephrectomy is now usually reserved for tumors in which embolization would be difficult, if the AML vascular anatomy is complex, if embolization fails, or if malignancy is suspected.27,34-36 It offers complete removal of the tumor and allows for histological evaluation. It is also associated with a lower recurrence of disease when compared to embolization, and does not increase the frequency of complications. 36

In our patient, end stage renal failure was present. This prompted consideration of a nephrectomy, which was subsequently performed in order to limit the increase in renal volume. Nephrectomy was performed via lumbotomy with an extraperitoneal approach to protect the integrity of the peritoneum as well as avoid infection of the subcutaneous tunnel and the catheter exit site. The patient and her family have tolerated well the peritoneal dialysis procedure. However, it should be underscored that this procedure must be maintained for long periods; but in subjects with an intellectual disability, such as in our patient, kidney transplantation is not excluded when there is an adequate social support network. 37

In this case, with the detailed histopathologic examination following the nephrectomy, a RCC of the right kidney was also discovered. We recommend nephrectomy in TSC, especially in young patients, immediately after the dialysis procedure and before performing transplantation, to avoid frequent invasive check-ups of the native kidneys and the risks of malignant tumor development.

A multidisciplinary approach including pediatric surgeons, pediatric nephrologists and interventional radiologists should be pursued for all patients undergoing renal embolization. Preinterventional planning and careful monitoring for complications are recommended to optimize clinical outcomes.

\section{Conclusions}

We showed that urgent selective renal $\mathrm{AE}$ represents a feasible treatment for bilateral AML bleeding. Renal AE in patients with end-stage renal failure is safe and feasible before performing nefrectomy. Early identification of AML and periodic surveillance in patients with TSC is necessary after the initial diagnosis to ensure optimal care and prevention of future complications and tumor degeneration. ${ }^{14} \mathrm{~A}$ multidisciplinary team provides comprehensive care and follow up in patients with renal failure and has perspectives for renal transplantation.

\section{References}

1. Grenier N, Petitpierre F, Le Bras Y, Lasserre AS, Cornelis F. Renal embolization. Nephrol Ther 2016;12: S139-43.

2. Ramaswamy RS, Akinwande O, Tiwari T. Renal embolization: Current recommendations and rationale for clinical practice. Curr Urol Rep 2018; 19:5.

3. Bourneville DM. Contribution à l'etude de l'idiotie. Sclerose tuberuse des circonvolutions cerebrales; idiotie et eiplepsie hemiplegique. Arch Neurol 1880;1:81.

4. Gomez MR. Phenotypes of the tuberous sclerosis complex with a revision of diagnostic criteria. Ann N Y Acad Sci 1991;615:1-73.

5. Crino PB, Nathanson KL, Henske EP. The tuberous sclerosis complex. N Engl J Med 2006;355:1345-64.

6. Crino PB. Evolving neurobiology of tuberous sclerosis complex. Acta Neuropathol. 2013;125:317-32.

7. Lie JT. Cardiac, pulmonary and vascular involvements in tuberous sclerosis. Ann 
N Y Acad Sci 1991; 615:58-70 .

8. Rakowski SK, Winterkorn EB, Paul E, et al. Renal manifestations of tuberous sclerosis complex: Incidence, prognosis, and predictive factors. Kidney Int 2006;70:1777-82.

9. Dhakal M, Dhakal OP, Bhandari D. Polycystic kidney disease and chronic renal failure in tuberous sclerosis. BMJ Case Rep 2013;2013.

10. Nelson CP, Sanda MG. Contemporary diagnosis and management of renal angiomyolipoma. J Urol 2002;168: 1315-25.

11. O'Callaghan FJ, Noakes MJ, Martyn CN et al. An epidemiological study of renal pathology in tuberous sclerosis complex. BJU Int 2004;94:853-7.

12. Prakash G, Sankhwar S, Jhanwar A, Singh K. Bilateral renal angiomyolipoma presenting as tuberous sclerosis syndrome. BMJ Case Rep 2016;11: 2016.

13. Wang C, Yang M, Tong X, Wang J, Guan H, Niu G, Yan Z, Zhang B, Zou Y. Transarterial embolization for renal angiomyolipomas: A single centre experience in 79 patients. J Int Med Res 2017;45:706-13.

14. Krueger DA, Northrup H; International Tuberous Sclerosis Complex Consensus Group. Tuberous sclerosis complex surveillance and management: recommendations of the 2012 International Tuberous Sclerosis Complex Consensus Conference. Pediatr Neurol 2013;49:255-65.

15. Kingswood JC, Bissler JJ, Budde K, et al. Review of the Tuberous Sclerosis Renal Guidelines from the 2012 Consensus Conference: Current Data and Future Study. Nephron 2016;134:51-8.

16. Bardin F, Chevallier O, Bertaut A, et al. Selective arterial embolization of symptomatic and asymptomatic renal angiomyolipomas: a retrospective study of safety, outcomes and tumor size reduction. Quant Imaging Med Surg 2017;7:8-23.

17. Wang H, Long Q, Wang Y, Liu L, Zhou L, Guo J. Tuberous sclerosis complexassociated renal angiomyolipomas: A single center study of 17 consecutive cases. Oncol Lett 2016;12:1501-6.

18. Thiravit S, Teerasamit W, Thiravit P. The different faces of renal angiomyolipomas on radiologic imaging: a pictorial review. Br J Radiol
2018;91:20170533.

19. Furlano M, Barreiro Y, Martí T, Facundo C, Ruiz-García C, DaSilva I, Ayasreh N, Cabrera-López C, Ballarín J, Ars E, Torra R. Renal angiomyolipoma bleeding in a patient with TSC2/PKD1 contiguous gene syndrome after 17 years of renal replacement therapy. Nefrologia 2017;37:87-92.

20. Brakemeier S, Vogt L, Adams L, et al. Treatment effect of mTOR-inhibition on tissue composition of renal angiomyolipomas in tuberous sclerosis complex (TSC). PLoS One 2017; 12:e0189132.

21. Krueger DA, Capal JK, Curatolo P, et al. Short-term safety of mTOR inhibitors in infants and very young children with tuberous sclerosis complex (TSC): Multicentre clinical experience. Eur J Paediatr Neurol 2018:S10903798(17)31969-4.

22. Bissler JJ, Kingswood JC, Radzikowska E, et al. Everolimus long-term use in patients with tuberous sclerosis complex: Four-year update of the EXIST-2 study. PloS One 2017; 12:e0180939.

23. Bissler JJ, Kingswood JC, Radzikowska E, et al. Everolimus for angiomyolipoma associated with tuberous sclerosis complex or sporadic lymphangioleiomyomatosis (EXIST-2): A multicentre, randomised, double-blind, placebo-controlled trial. Lancet 2013;381:817-24.

24. Kingswood JC, Belousova E, Benedik $\mathrm{MP}$, et al. Renal angiomyolipoma in patients with tuberous sclerosis complex: findings from the TuberOus SClerosis registry to increase disease Awareness. Nephrol Dial Transplant 2019;34:502-8.

25. Dabbeche C, Chaker M, Chemali R, et al. Role of embolization in renal angiomyolipomas. J Radiol 2006;87: 1859-67.

26. Guziński M, Kurcz J, Tupikowski K, et al. The Role of transarterial embolization in the treatment of renal tumors. Adv Clin Exp Med 2015;24:837-43.

27. Jo-Hoy F, Tolaymat O, Kunjal R, James LR. Tuberous sclerosis and bilateral renal angiomyolipomas: A case report and literature review of emerging treatment strategies. Case Rep Nephrol 2016;2016:4595014.

28. Van Rooijen JM, De Vries EG. Hemodialysis no reason to withhold everolimus. Cancer Chemother Pharmacol 2013;71:273-4.

29. Janus N, Thariat J, Boulanger H, et al. Proposal for dosage adjustment and timing of chemotherapy in hemodialyzed patients. Ann Oncol 2010;21:1395-403.

30. Thiery-Vuillemin A, Curtit E, Maurina $\mathrm{T}$, et al. Hemodialysis does not affect everolimus pharmacokinetics: two cases of patients with metastatic renal cell cancer. Ann Oncol 2012;23:2992-3.

31. Syrios J, Kechagias G, Tsavaris N. Treatment of patients with metastatic renal cell carcinoma undergoing hemodialysis: case report of two patients and short literature review. BMC Nephrol 2013;14:84.

32. Aditya V, Matrana MR, Atkinson BJ, et al. Outcomes of patients with metastatic renal cell carcinoma and end-stage renal disease receiving dialysis and targeted therapies: a single institution experience. Clin Genitourin Cancer 2014;12:34853.

33. Czarnecka AM, Kawecki M, Lian F, et al. Feasibility, efficacy and safety of tyrosine kinase inhibitor treatment in hemodialyzed patients with renal cell cancer: 10 years of experience. Future Oncol 2015;11:2267-82.

34. Murray TE, Doyle F, Lee M. Transarterial embolization of angiomyolipoma: a systematic review. J Urol 2015;194:635-9.

35. Eijkemans MJC, van der Wal W, Reijnders LJ, et al. Long-term follow-up assessing renal angiomyolipoma treatment patterns, morbidity, and mortality: an observational study in tuberous sclerosis complex patients in the Netherlands. Am J Kidney Dis 2015;66:638-45.

36. Lee SY, Hsu HH, Chen YC, et al. Embolization of renal angiomyolipomas: short-term and longterm outcomes, complications, and tumor shrinkage. CardioVasc Intervent Radiol 2009;32:1171-8.

37. Faddegon S, So A. Treatment of angiomyolipoma at a tertiary care centre: the decision between surgery and angioembolization. J Canad Urol Assoc 2011;5:E138-41.

38. Chen A, Farney A, Russell GB, et al. Severe intellectual disability is not a contraindication to kidney transplantation in children. Pediatr Transplant 2017;21. 